\title{
Various Scoring Systems for Predicting Revascularization of Chronic Coronary Total Occlusion by Percutaneous Coronary Intervention
}

\author{
Binay Kumar Adhikari, Shudong Wang, Cheng Li, Yonggang Wang, Weihua Zhang, \\ Quan Liu* \\ Department of Cardiovascular Medicine, The First Hospital of Jilin University, Changchun, China \\ Email: bka4adhikari@hotmail.com,wsd816@163.com, licheng7011@126.com,xiaogang94@163.com,zwhcyzb@qq.com, \\ *quanliu888@163.com
}

How to cite this paper: Adhikari, B.K., Wang, S.D., Li, C., Wang, Y.G., Zhang, W.H. and Liu, Q. (2019) Various Scoring Systems for Predicting Revascularization of Chronic Coronary Total Occlusion by Percutaneous Coronary Intervention. World Journal of Cardiovascular Diseases, 9 , 385-393.

https://doi.org/10.4236/wjcd.2019.96034

Received: February 1, 2019

Accepted: June 7, 2019

Published: June 10, 2019

Copyright $\odot 2019$ by author(s) and Scientific Research Publishing Inc. This work is licensed under the Creative Commons Attribution International License (CC BY 4.0).

http://creativecommons.org/licenses/by/4.0/ (c) (i) Open Access

\begin{abstract}
Successful revascularization of chronic total occlusion (CTO) by percutaneous coronary intervention (PCI) is associated with reduced major adverse cardiovascular events (MACEs) compared with CTO PCI failure. The developments of new strategies and new devices have improved the success rate of CTO PCI. However, the complexity of CTO lesions, clinical characteristics of patients and operator experience highly determine the successful revascularization. Using search items, "chronic total occluion", "percutaneous coronary intervention", "scoring systems", "predictablity". We searched Pubmed, ScienceDirect, Web of Science, Cochrane Library, and CNKI. We found six clinically used scoring systems from 2011 to 2018. They included J-CTO score, CT-RECTOR score, CL score, PROGRESS CTO score, ORA score, and Ellis score. All parameters of each scoring systems have been systematically reviewed. The patients with higher score have found to have a decreased probability of CTO recanalization. Ellis score that mainly focused on ambiguous proximal cap and hybrid approach seems to provide better predictability in deciding procedure strategy.
\end{abstract}

\section{Keywords}

Chronic Total Occlusion, Percutaneous Coronary Intervention, Predictability

\section{Introduction}

Percutaneous revascularization of coronary chronic total occlusion is a techni- 
cally challenging procedure in interventional cardiology worldwide [1]. Although, success rate of treating these occlusions is only $65 \%-70 \%$ even in experienced hands [2], significant clinical benefits to the patients has been associated after successful CTO recanalization [3]. These benefits include improved symptoms of angina and dyspnoea, decrease need for anti-anginal medications, improved left ventricular function, decreased need for CABG, and improved survival [4] [5]. However, several factors influence its success especially patient clinical characteristics, lesion complexity, and operator experience [6]. Hence, various scoring systems were developed (i.e. J-CTO score, CT-RECTOR score, CL score, PROGRESS CTO score, ORA score, and Ellis score) (Table 1) to predict the probability of successful intervention and a better selection of both patient and operator. Here, we discuss these scoring systems and compare their validity and efficacy in predicting successful revascularization in CTO patient.

\section{Scoring Systems}

We searched Pubmed, ScienceDirect, Cochrane Library, Web of Science, and CNKI for articles from 2011 to 2018. Search items were "chronic total occlusion", "percutaneous coronary intervention", "scoring systems", "predictablity". We selected six clinically used scoring systems. The first and globally accepted scoring system (J-CTO score) was developed in 2011 by Morino et al. [7] Independent predictors included blunt stump, calcification, bending, occlusion length $>20 \mathrm{~mm}$, and previously failed attempt. After several years J-CTO score, CT-RECTOR (Computed tomography registry of chronic total occlusion revascularization) score was developed by Opolski et al. in 2015 [8]. It used non-invasive investigation of coronary computed tomography angiography to predict difficult in CTO re-vascularization. A total of 240 consecutive CTO lesions from 4 centres in Germany were analysed. They also predicted the probability of successful guidewire crossing $\leq 30 \mathrm{~min}$. All CCTA were performed 4 weeks prior to percutaneous coronary intervention. Six independent predictors were included i.e. presence of multiple occlusion, blunt stump at entry or exit site, severe calcification, bending $\geq 45^{\circ}$, previously failed PCI at CTO, and duration of CTO $\geq 12$ months or unknown. Clinical and Lesion (CL) related score was presented by Alessandrino et al. to predict PCI success in CTO [9]. It was developed based on both clinical and angiographic parameters of 1671 consecutive patients with CTO lesion. Successful procedure was defined as the achievement of $<30 \%$ residual diameter stenosis as assessed by CAG and associated with TIMI grade 3 . Independent predictive variables were severely calcified lesion, previous CABG, lesion length $\geq 20 \mathrm{~mm}$, previous MI, blunt stump, and non-LAD CTO location, and were scored according to their odd ratio. Only severe calcification was assigned as independent predictor.

In 2016, Christopoulos et al. developed a novel parsimonious score (PROGRESS CTO) to predict technical success of CTO PCI performed using hybrid approach [10]. Technical success was defined as successful CTO revascularization with $<30 \%$ residual diameter stenosis within the treated segment and 
Table 1. General information on scoring systems.

\begin{tabular}{|c|c|c|c|c|c|}
\hline Scoring system & $\begin{array}{l}\text { Published } \\
\text { year }\end{array}$ & $\begin{array}{l}\text { No. of } \\
\text { CTO } \\
\text { patients }\end{array}$ & Primary endpoint & Predictors & Predictability \\
\hline J-CTO & 2011 & 465 & $\begin{array}{l}\text { Guidewire crossing } \\
\text { within } 30 \text { minutes }\end{array}$ & $\begin{array}{l}\text { 1) Entry shape (1) } \\
\text { 2) Calcification (1) } \\
\text { 3) Bending }>45^{\circ}(1) \\
\text { 4) Occlusion length (1) } \\
\text { 5) Re-entry lesion (1) }\end{array}$ & $\begin{array}{l}\text { 1) Easy: Score } 0 \\
\text { 2) Intermediate: Score } 1 \\
\text { 3) Difficult: Score } 2 \\
\text { 4) Very difficult: Score } \geq 3\end{array}$ \\
\hline $\begin{array}{c}\text { CT } \\
\text { RECTOR }\end{array}$ & 2015 & 240 & $\begin{array}{l}\text { Guidewire crossing } \\
\text { within } 30 \text { minutes }\end{array}$ & $\begin{array}{l}\text { 1) Multiple occlusions (1) } \\
\text { 2) Blunt stump (1) } \\
\text { 3) Severe calcification (1) } \\
\text { 4) Bending }>45^{\circ} \text { (1) } \\
\text { 5) Second attempt (1) } \\
\text { 6) Duration of CTO (1) }\end{array}$ & $\begin{array}{l}\text { 1) Easy: Score } 0 \\
\text { 2) Intermediate: Score } 1 \\
\text { 3) Difficult: Score } 2 \\
\text { 4) Very difficult: Score } \geq 3\end{array}$ \\
\hline CL & 2015 & 1657 & $\begin{array}{l}\text { Procedural success } \\
\text { defined by }<30 \% \\
\text { residual diameter } \\
\text { stenosis with TIMI } \\
\text { grade } 3\end{array}$ & $\begin{array}{l}\text { 1) Severe calcified lesion (2) } \\
\text { 2) Previous CABG (1.5) } \\
\text { 3) Lesion length } \geq 20 \mathrm{~mm} \text { (1.5) } \\
\text { 4) Previous MI (1) } \\
\text { 5) Blunt stump (1) } \\
\text { 6) Non-LAD CTO location (1) }\end{array}$ & $\begin{array}{l}\text { 1) High: } \leq 1 \\
\text { 2) Intermediate: }<3 \\
\text { 3) Low: }<5 \\
\text { 4) Very low: } \geq 5\end{array}$ \\
\hline PROGRESS CTO & 2016 & 781 & $\begin{array}{l}\text { Technical success } \\
\text { defined by }<30 \% \\
\text { residual diameter } \\
\text { stenosis with TIMI } \\
\text { grade } 3\end{array}$ & $\begin{array}{l}\text { 1) Proximal cap ambiguity (1) } \\
\text { 2) Absence of interventional collaterals (1) } \\
\text { 3) Moderate/severe tortuosity (1) } \\
\text { 4) Circumflex CTO (1) }\end{array}$ & $\begin{array}{l}\text { The higher score, the lower } \\
\text { technical success }\end{array}$ \\
\hline ORA & 2016 & 1073 & $\begin{array}{c}\text { Technical success } \\
\text { defined by final residual } \\
\text { stenosis }<20 \% \text { and } \\
\text { TIMI grade } 3\end{array}$ & $\begin{array}{l}\text { 1) Ostial location } \\
\text { 2) Rentrop collateral filling } \\
\text { 3) Age }\end{array}$ & $\begin{array}{l}\text { 1) Easy: Score } 0 \\
\text { 2) Intermediate: Score } 1 \\
\text { 3) Difficult: Score } 2 \\
\text { 4) Very difficult: Score } \geq 3\end{array}$ \\
\hline Ellis score & 2017 & 436 & $\begin{array}{l}\text { Technical success } \\
\text { defined by restoration } \\
\text { of TIMI flow grade } 3 \\
\text { and no stenosis }>50 \%\end{array}$ & $\begin{array}{l}\text { 1) Ambiguous cap proximal cap } \\
\text { 2) Collateral score } \\
\text { 3) Tortuosity } \\
\text { 4) Calcification } \\
\text { 5) Poor distal target } \\
\text { 6) Length }>10 \mathrm{~mm} \\
\text { 7) Ostial location } \\
\text { 8) Operator G }\end{array}$ & $\begin{array}{l}\text { The higher score, the lower } \\
\text { technical success }\end{array}$ \\
\hline
\end{tabular}

restoration of TIMI flow grade 3. A total of 781 CTO patients were analysed clinically and angiographically. Four variables were assigned considering their strong association with technical success of CTO. Variables were proximal cap ambiguity, absence of interventional collaterals, moderate/severe tortuosity, circumflex CTO. Circumflex CTO was predicted as a factor associated with technical failure because of its relatively increased tortuosity, the less frequent presence of interventional collaterals, and hence lower success rate. Alfredo et al. developed a novel predictive score that included Ostial location, Rentrop collateral filling grade, and Age (ORA) [11]. Although univariate correlates of technical failure included age $\geq 75$ years, history of MI, prior PCI, left ventricular ejection 
fraction $<50 \%$, previous attempt, ostial location, blunt stump, collateral filling Rentrop grade $<2$, disease of distal segment of CTO artery, multivariable analysis only found 3 variables (age $\geq 75$, Rentrop grade $<2$, and ostial location) as independent predictors of technical failure.

Recently, Ellis et al. developed Ellis score for predicting successful hybrid-approach chronic total coronary artery occlusion stenting in 2017 [12]. According to them, the initial determination of difficult revascularization is dependent on ambiguous cap proximal cap. Other predictors included specifically defined collateral score (combination of Werner and tortuosity scores), retrograde tortuosity, poor distal target, occlusion length $>10 \mathrm{~mm}$, ostial location, and 1 operator variable.

\section{Discussions}

Several factors influence successful CTO revascularization by percutaneous coronary intervention. These factors can be broadly classified as patient related factors and operator related factors. Additionally, patient related factors can be further divided into clinical related and CTO lesion related factors. We have already mentioned several predictive scoring systems for procedural and technical success. Some predictive factors are common among scoring systems while some are specific to a specific scoring system. Similarly, procedural success is heavily dependent on operator experience and expertise [13]. Experienced operators can achieve $>85 \%$ of success rates even in complex and difficult patient groups [14]. However, reopening rate is only $60 \%$ when performed by less experienced operators. In these cases, patient may need CABG because of unsuccessful percutaneous intervention [15]. Sharma et al. and Scott et al. emphasized the need of proctorship to improve CTO PCI skills, and found useful in patients with J-CTO score $\geq 2$ with success rate improving from $49.5 \%$ to $70.7 \%$ [16] [17].

J-CTO score was widely used before the development of other scoring systems. Recently, the impact of J-CTO score on procedural outcome and target lesion revascularization after PCI was also studied by Hiroyuki et al. [18]. The TLR rates at 1 year were $5.3 \%, 11.1 \%, 16.7 \%$, and $13.4 \%$ of patients with J-CTO score of $0,1,2$, and $\geq 3$ respectively. Patients with lower J-CTO score achieved a high procedural success rate and increased TLR-free survival rate. In case of multiple occlusion and severe calcification, CCTA would be a better choice than coronary angiography and studies have also demonstrated that severe calcification is independently related to successful CTO PCI [19]. Studies have shown CTO lesions with severe calcification involving $\geq 50 \%$ of vessel cross sectional area are more prone to PCI failure [20]. Additionally, different stages of CTO also influence revascularization success. An early stage/short duration CTO has more favourable procedural outcome than the late stage/long duration CTO [21]. CTO duration was also emphasized in CT-RECTOR score. According to Yahang et al. [22], CT-RECTOR score represents more accurate non-invasive tool in predicting time-efficient GW crossing than J-CTO score.

In addition to lesion complexity, clinical variables have also shown negative 
impact on procedural success. According to Guelker et al. [23], CL score predicted more precisely the interventional results than the J-CTO score. However, only the first attempt patients were enrolled in CL score, and the majority of them were performed via antegrade approach. Hence, it is applicable only in centres when retrograde/hybrid approach is not performed. Besides, low rate of contralateral injection, less radiation exposure, relatively low success rate is observed in CL scoring system. The PROGRESS CTO scoring system does not include prior CTO PCI failure, which according to Christopoulos et al., highly dependent on experience and expertise of operator who performs the procedure. The primary endpoint in J-CTO score is guidewire crossing time $<30 \mathrm{~min}$, while PROGRESS CTO don't care about the procedural duration, its primary outcome measure is procedural success, defined by $<30 \%$ residual stenosis with TIMI grade 3. Specific features including the advantages and disadvantages of different scoring systems are listed in Table 2. PROGRESS CTO score utilizes hybrid algorithm that values proximal cap ambiguity, and presence of interventional collaterals. The lower success rates for circumflex CTO target vessel is likely related to increased tortuosity of this vessel and the less frequent presence of interventional collaterals. ORA score includes age, ostial location and Rentrop collateral filling. Age $\geq 75$ years is predicted as a factor for technical failure in ORA score. Both scores predicted technical failure using both antegrade and retrograde CTO

Table 2. Specific features of different scoring systems.

\begin{tabular}{|c|c|}
\hline Scoring system & Specific features \\
\hline J-CTO score & $\begin{array}{l}\text { - First and widely used } \\
\text { - Applicable both for antegrade and retrograde approach } \\
\text { - Operator bias excluded }\end{array}$ \\
\hline CT RECTOR score & $\begin{array}{l}\text { - } \\
\text { - } \text { Open-invasive } \\
\text { - } \text { Severe calcification used as predictor } \\
\text { - } \quad \text { Multiple occlusions were best seen by coronary CTA }\end{array}$ \\
\hline CL score & $\begin{array}{l}\text { - } \text { Both clinical and angiographic parameters } \\
\text { - Only the first attempt included } \\
\text { - Applicable mostly for antegrade approach }\end{array}$ \\
\hline PROGRESS CTO score & $\begin{array}{l}\text { - Not include prior CTO PCI failure } \\
\text { - Applicable for hybrid approach } \\
\text { - } \text { Final angiographic success as primary endpoint } \\
\text { - } \text { Circumflex CTO as an independent predictor }\end{array}$ \\
\hline ORA score & $\begin{array}{l}\text { - Simple and easy to remember } \\
\text { - Only } 3 \text { variables } \\
\text { - Applicable both for antegrade and retrograde approach } \\
\text { - Included clinical and angiographic parameters }\end{array}$ \\
\hline Ellis score & $\begin{array}{l}\text { - Improved model with powerful predictors } \\
\text { - Applicable for hybrid approach } \\
\text { - } \text { Complex definition for interventional collateral vessels } \\
\text { - } \text { Operator G as an independent predictor }\end{array}$ \\
\hline
\end{tabular}


techniques. J-CTO score is developed by multi centre CTO registries in Japan, while ORA score is a single centre, single operator study, hence its validation in large cohorts of patients will be required to expand its use in CTO PCI.

Ellis score primarily focused on ambiguous proximal cap and emphasis on its presence being the main cause of CTO PCI failure, which we think is a powerful predictor in deciding the strategy. Similarly, the presence of interventional collateral vessels also helps in deciding alternative approaches. This model achieved higher technical success which was significantly higher than J-CTO (0.55) and PROGRESS-CTO (0.61). By including collateral score, tortuosity, calcification, poor distal target, ambiguous proximal cap, it is probably a comprehensive scoring system. The major limitation of our study is that there was no comparative patient based study that could better assess the predictability of scoring systems. It needs clinical studies to compare its specificity and sensitivity with other scoring systems.

\section{Conclusion}

Successful CTO revascularization by PCI significantly reduces clinical symptoms due to ischemia, improves left ventricular function, reduces CABG, and improves prognosis. Several patient related and operator related factors influence procedural outcome of CTO revascularization, which are emphasized by different scoring systems. In all scoring systems, patients with higher difficulty predictive score have lower probability to CTO revascularization. Hence, in those patients, CABG is better preferred to avoid unnecessary radiation and contrast burden, or refer to a high volume CTO PCI centre where different approaches and adjuvant modalities are utilized and highly experienced operators perform CTO PCI. The Ellis score has improved predictability compared with other scoring systems that followed hybrid approach. The predictability of this score for Japanese approach and APCTO algorithm needs to be studied. Additionally, it needs clinical studies to compare its specificity and sensitivity with other scoring systems.

\section{Conflicts of Interest}

The authors declare no conflicts of interest regarding the publication of this paper.

\section{References}

[1] Galassi, A.R., Brilakis, E.S., Boukhris, M., et al. (2016) Appropriateness of Percutaneous Revascularization of Coronary Chronic Total Occlusion: An Overview. European Heart Journal, 37, 2692-2700. https://doi.org/10.1093/eurheartj/ehv391

[2] Suero, J.A., Marso, S.P., Jones, P.G., Laster, S.B., Huber, K.C., et al. (2001) Procedural Outcomes and Long-Term Survival among Patients Undergoing Percutaneous Coronary Intervention of a Chronic Total Occlusion in Native Coronary Arteries: A 20 Year Experience. Journal of the American College of Cardiology, 38, 409-414. https://doi.org/10.1016/S0735-1097(01)01349-3 
[3] Christakopoulos, G.E., Christopoulos, G., Carlino, M., Jeroudi, O.M., Roesle, M., Rangan, B.V., Abdullah, S., Grodin, J., Kumbhani, D.J., Vo, M., Luna, M., et al. (2015) Meta-Analysis of Clinical Outcomes of Patients Who Underwent Percutaneous Coronary Interventions for Chronic Total Occlusions. The American Journal of Cardiology, 115, 1367-1375. https://doi.org/10.1016/j.amjcard.2015.02.038

[4] Roxana, M., Bimmer, E.C., Cosmo, G., George, D.D., et al. (2011) Long Term Outcome of Percutaneous Coronary Intervention for Chronic Total Occlusions. JACC: Cardiovascular Intervention, 4, 953-961.

[5] James, S., Adam, C.S., Robert, W.Y., et al. (2017) Early Procedural and Health Status Outcomes after Chronic Total Occlusion Angioplasty: A Report from the OPEN-CTO Registry (Outcomes, Patient Health Status, and Efficiency in Chronic Total Occlusion Hybrid Procedures). JACC: Cardiovascular Interventions, 10, 1524-1534.

[6] Michael, T.T., Karmapaliotis, D., Brilakis, E.S., Fuh, E., Patel, V.G., et al. (2013) Procedural Outcomes of Revascularization of Chronic Total Occlusion of Native Coronary Arteries (from a Multicentre Unites States Registry). The American Journal of Cardiology, 112, 488-492. https://doi.org/10.1016/j.amjcard.2013.04.008

[7] Morino, Y., Abe, M., Morimoto, T., Kimura, T., Hayashi, Y., Muramatsu, T., Ochiai, M., et al. (2011) Predicting Successful Guidewire Crossing through Chronic Total Occlusion of Native Coronary Lesions within 30 Minutes: The J-CTO (Multicenter CTO Registry in Japan) Score as a Difficulty Grading and Time Assessment Tool. JACC: Cardiovascular Interventions, 4, 213-221.

https://doi.org/10.1016/j.jcin.2010.09.024

[8] Maksyamilian, P.O., Stephan, A., Annika, S., Rolf, A., et al. (2015) Coronary Computed Tomographic Prediction Rule for Time-Efficient Guidewire Crossing through Chronic Total Occlusion: Insights from CT-RECTOR Multicentre Registry (Computed Tomography Registry of Chronic Total Occlusion Revascularization). JACC: Cardiovascular Interventions, 8, 257-267. https://doi.org/10.1016/j.jcin.2014.07.031

[9] Alessandrino, G., Chevalier, B., Lefevre, T., Sanguineti, F., Garot, P., Unterseeh, T., et al. (2015) A Clinical and Angiographic Scoring System to Predict the Probability of Successful First-Attempt Percutaneous Coronary Intervention in Patients with Total Chronic Coronary Occlusion. JACC: Cardiovascular Interventions, 8, 1540-1548. https://doi.org/10.1016/j.jcin.2015.07.009

[10] Christopoulos, G., Kandzari, D.E., Yeh, R.W., Jaffer, F.A., Karmapaliotis, D., Wyman, M.R., et al. (2016) Development and Validation of a Novel Scoring System for Predicting Technical Success of Chronic Total Occlusion Percutaneous Coronary Interventions: The PROGRESS CTO (Prospective Global Registry for the Study of Chronic Total Occlusion Intervention) Score. JACC: Cardiovascular Interventions, 9, 1-9. https://doi.org/10.1016/j.jcin.2015.09.022

[11] Alfredo, R.G., Marouane, B., Salvatore, A., Marine, C., et al. (2016) Percutaneous Coronary Revascularization for Chronic Total Occlusions: A Novel Predictive Score of Technical Failure Using Advanced Technologies. JACC: Cardiovascular Interventions, 9, 912-922. https://doi.org/10.1016/j.jcin.2016.01.036

[12] Stephen, G.E., Burke, M.N., Murad, M.B., et al. (2017) Predictors of Successful Hybrid-Approach Chronic Total Coronary Artery Occlusion Stenting: An Improved Model with Novel Correlates. JACC: Cardiovascular Interventions, 10, 1089-1098. https://doi.org/10.1016/j.jcin.2017.03.016

[13] Michael, T.T., Karmapaliotis, D., Brilakis, E.S., et al. (2015) Temporal Trends of Fluoroscopy Time and Contrast Utilization in Coronary Chronic Total Occlusion Revascularization: Insights from a Multicentre United States Registry. Catheteriza- 
tion and Cardiovascular Interventions, 85, 393-399. https://doi.org/10.1002/ccd.25359

[14] Christopoulos, G., Menon, R.V., Karmpaliotis, D., Alaswad, K., Lombardi, W., et al. (2014) Application of the "Hybrid Approach" to Chronic Total Occlusions in $\mathrm{Pa}$ tients with Previous Coronary Artery Bypass Graft Surgery (from a Contemporary Multicentrer US Registry). The American Journal of Cardiology, 113, 1990-1994. https://doi.org/10.1016/j.amjcard.2014.03.039

[15] Edward, L.H., Ye, Z., Alice, K.J., et al. (2016) Patients with Chronic Total Occlusions Undergoing Percutaneous Coronary Interventions. Characteristics, Success and Outcomes. Circulation: Cardiovascular Interventions, 9, 1-9. https://doi.org/10.1161/CIRCINTERVENTIONS.116.003586

[16] Sharma, V., Jadhav, S.T., Harcombe, A.A., et al. (2015) Impact of Proctoring on Success Rates for Percutaneous Revascularisation of Coronary Chronic Total Occlusions. Open Heart, 2, Article No. e000228. https://doi.org/10.1136/openhrt-2014-000228

[17] Scott, A.H., Eugene, B., Sidney, L., Soo, T.L., et al. (2017) A New Algorithm for Crossing Chronic Total Occlusions from the Asia Pacific Chronic Total Occlusion Club. JACC: Cardiovascular Interventions, 10, 2135-2143. https://doi.org/10.1016/j.jcin.2017.06.071

[18] Tanaka, H., Morino, Y., Abe, M., Kimura, T., et al. (2016) Impact of J-CTO Score on Procedural Outcome and Target Lesion Revascularisation after Percutaneous Coronary Intervention for Chronic Total Occlusion: A Substudy of the J-CTO Registry (Multicentre CTO Registry in Japan). EuroIntervention Journal, 11, 981-988. https://doi.org/10.4244/EIJV11I9A202

[19] Mollet, N.R., Hoye, A., Lemos, P.A., et al. (2005) Value of Preprocedure Multislice Computed Tomographic Coronary Angiography to Predict the Outcome of Percutaneous Recanalization of Chronic Total Occlusions. The American Journal of Cardiology, 95, 240-243. https://doi.org/10.1016/j.amjcard.2004.09.009

[20] Rolf, A., Werner, G.S., Schuhback, A., et al. (2014) Preprocedural Coronary CT Angiography Significantly Improves Success Rates of PCI for Chronic Total Occlusion. The International Journal of Cardiovascular Imaging, 29, 1819-1827. https://doi.org/10.1007/s10554-013-0258-y

[21] Katsuragawa, M., Fujiwara, H., Miyamae, M., et al. (1993) Histologic Studies in Percutaneous Transluminal Coronary Angioplasty for Chronic Total Occlusion: Comparison of Tapering and Abrupt Types of Occlusion and Short and Long Occluded Segments. Journal of the American College of Cardiology, 21, 604-611. https://doi.org/10.1016/0735-1097(93)90091-E

[22] Yahang, T., Jia, Z., Wei, Z., Ying, Z., et al. (2017) Comparison of CT-RECTOR and J-CTO Scores to Predict Chronic Total Occlusion Difficulty for Percutaneous Coronary Intervention. International Journal of Cardiology, 235, 169-175. https://doi.org/10.1016/j.ijcard.2017.02.008

[23] Guelker, J.E., Bansemir, L., Ott, R., et al. (2017) Validity of the J-CTO Score and the CL-Score for Predicting Successful CTO Recanalization. International Journal of Cardiology, 230, 228-231. https://doi.org/10.1016/j.ijcard.2016.12.165 


\section{Abbreviations}

CABG = Coronary Artery Bypass Graft;

$\mathrm{CAG}=$ Coronary Angiography;

CCTA = Coronary Computed Tomography Angiography;

$\mathrm{CCTO}=$ Coronary Chronic Total Occlusion;

CL Score $=$ Clinical and Lesion Related Score;

$\mathrm{CTO}=$ Chronic Total Occlusion;

CT-RECTOR Score $=$ Computed Tomography Registry of Chronic Total

Occlusion Revascularization;

J-CTO Score = Japanese Chronic Total Occlusion Score;

ORA Score = Ostial Location, Rentrop Collateral Grade, Age Score;

$\mathrm{PCI}=$ Percutaneous Coronary Intervention;

PROGRESS CTO Score $=$ Prospective Global Registry for the Study of

Chronic Total Occlusion Intervention Score;

TIMI Grade = Thrombolysis in Myocardial Infarction Grade;

$\mathrm{TLR}=$ Target Lesion Revascularization . 